\title{
Content mediation and digital technology in museums: design strategies to enrich the visitor's experience
}

\author{
Diego Enéas Peres Ricca \\ FAU USP | Brazil | diego.ricca.p@gmail.com
}

\section{SIGRADI2018 TECHNOPOLITICAS \\ xxii congresso da sociedade iberoamericana de gráfica digital 22th conference of the iberoamerican society of digital graphics 07|08|09|novembro|2018 iau usp | são carlos | sp br}

Dra. Clice de Toledo Sanjar Mazzilli

FAU USP | Brazil | clice@usp.br

\begin{abstract}
This paper aims to identify design strategies that integrate digital computational technologies to artifacts and installations for the interaction of museum visitors. Elements that enable the visitation experience to be satisfactory are identified through a recognition study of proposals for content mediating artifacts in museums based on theoretical aspects relevant to the understanding of human interaction with technology. It generates a classification of relevant design techniques from the cases listed on the analysis.
\end{abstract}

Keywords: Museum; Technology; Human-Computer Interaction; Cybernetics.

\section{INTRODUÇÃO}

A tecnologia digital se aplica de forma progressivamente maior e mais variada em diversos aspectos do cotidiano. $\mathrm{Na}$ trajetória de desenvolvimento dos museus - em decorrência ser uma instituição que possibilita transformação social, econômica e política - a digitalização destes espaços se apresenta como uma estratégia tomada por seus curadores e expositores a fim de proporcionar maior aproximação com o visitante, atraindo mais público e dando oportunidades para que este possa direcionar a sua própria experiência, tornando-o partícipe do que lhe é transmitido.

Tendo em vista a realidade brasileira, em que a maior parte da população nunca esteve em um museu ou uma instituição cultural, encontrar maneiras mais efetivas de transmissão de conteúdo possui impactos de ordem política e social, ao permitir um engajamento das instituições museológicas com camadas mais amplas da sociedade (Ogilvy et al., 2017, 0:12). Inspirado por tais questões, 0 presente artigo objetiva identificar estratégias projetuais para enriquecimento da experiência de visitação por meio de mediadores de conteúdo que integrem tecnologias computacionais digitais em museus. Busca-se isso visando refletir a respeito da interação e engajamento de visitantes em museus por meio da identificação, a partir da perspectiva do design, de elementos que possibilitem um enriquecimento da experiência de visitação.

É notório que há uma crescente busca, por parte do público geral, pelo uso de tecnologia digital em museus, e também uma necessidade crescente de mais investimento por parte do Ministério da Cultura com espaços culturais brasileiros (Gasparetto, 2014). O uso de interfaces responsivas, luzes, botões, sons e telas podem tornar-se meios importantes para a transmissão de conhecimento e engajamento do visitante. Cabe, entretanto, aqui ressaltar que a simples utilização de tais artefatos não torna automaticamente a experiência satisfatória, e uma série de elementos necessitam estar presentes ao contexto da atividade para que esta seja, de fato, enriquecedora para o usuário (Boelter, 2016). O projeto destas interfaces deve, portanto, estar aliado as necessidades dos visitantes, e pensar em ferramentas e estratégias que potencializem este engajamento se mostra como um caminho possível para pensar um design mais abrangente e engajado com a comunidade.
Tal ideal sugere um futuro promissor, entretanto, cabe refletir o papel de projetistas para fazer com que estes usos sejam satisfatórios, e não apenas uma fetichização do digital para que a instituição esteja devidamente inserida no século XXI. Marx traz o conceito de fetichismo tratando de um amplo contexto do uso dos produtos do trabalho humano, contrastando o seu valor real com o valor somado a relação social da valorização destes como mercadoria (Marx, 1985). Uma visão idealizada do uso de mídias digitais em museus faz com que, de maneira crescente, os curadores e expositores se vejam "obrigados" a dispor de tecnologia para que seus espaços sejam encaixados no cenário mercadológico vigente, podendo influenciar uma crescente propagação de usos superficiais destas tipologias de interfaces.

Segundo Meneses (2006) o fetiche é uma ferramenta largamente utilizada em museus, a qual "desloca os significados das coisas de sua produção para as coisas (elas próprias), como se fossem atributos imanentes (...)" (Meneses, 2006, p.06). A mediação tecnológica pode, muitas vezes, confundir-se com o objetivo em si, quando na verdade esta é um meio para que o usuário possa realizar sua interação com o ambiente, com os seus pares e consigo mesmo. Afinal, "tornar o museu mais atraente não pode ser um alvo em si, mas um recurso para melhor atingir os objetivos a que a instituição se propõe" (Furlaneto, 2013, on-line).

O processo de digitalização das mídias e dos artefatos é definidor do nosso tempo, provendo potenciais promissores dentro da própria noção imaterial que proporciona. Meneses (2009), por outro lado, defende que a materialidade em si não chegou a ser explorada em todo seu potencial, e que a larga profusão de elementos imateriais expõe falhas e incoerência na aplicação de mídias digitais, ao passar tão abruptamente do material para o imaterial sem que se tenha aprofundado nas possibilidades da primeira. Tal afirmação sugere que questões elementares da interação humana estão presentes tanto em formas de interação materiais como imateriais, e supervalorizar esta em detrimento daquela é um erro, pois a inclusão digital é aceitável somente quando está inserida dentro de contextos sociais, políticos, econômicos e culturais. Segundo o autor há um grande desinteresse pelos estímulos cognitivos nas exposições (Meneses, U. T. B. D., 2009). Entende-se, portanto, que o problema não é o uso da tecnologia em 
si, mas a reprodução acrítica e descontextualizada desta, estando mais centrada na troca de informação, do que na troca de conhecimento.

Boas ideias se apresentam como as bases para sustentar a comunicação bem-sucedida de conteúdo por meio de tecnologia digital em museus. Este artigo busca apontar tais possibilidades projetuais que direcionem caminhos que vão de encontro a inúmeros exemplos facilmente observados no cenário atual, nos quais, grandes quantidades de usos banais de ferramentas são aplicadas sem um maior aprofundamento, não provocando estímulos mais significativos nos visitantes, concentrando-se em aspectos superficiais da transmissão de informação. Tendo isso em vista, como, então, fazer com que mediadores de conteúdo sejam efetivamente meios de transmissão de conhecimento pela experiência, e não apenas entretenimento informativo? Volta-se, portanto, para tipologias de input e output interações em artefatos projetados a fim de se aproximar de uma reflexão a este respeito.

\section{MÉTODO}

Com a presente pesquisa não se pretende defender cegamente o uso de mediadores digitais de conteúdo em museus, e sim entender que aspectos projetuais podem ser explorados para tornar este uso mais significativo. Discute-se possibilidades de uso de ferramentas projetuais utilizadas para a produção de uma experiência atrativa para novos públicos, fazendo com que o conhecimento seja transmitido de forma mais lúdica e engajadora.

Apresenta-se, primeiramente, uma estruturação de um panorama teórico a partir de um levantamento centrado no entendimento de distintos autores a respeito das formas de resposta dos artefatos interativos aos estímulos humanos, ou seja, dos outputs presentes na interação usuário-máquina. Tais dados são apresentados como categorias, classificações e padrões apontados em livros, artigos, teses e dissertações, e são sistematizados aqui com 0 título de estratégias estruturais, em decorrência de se tratarem de classificações voltadas a aspectos mais técnicos e formais relativos ao projeto de artefatos interativos. Em seguida os pesquisadores apresentam sua contribuição por meio da identificação de categorias propostas pelos autores deste artigo a partir de um estudo de conceitos projetuais que tendem a fomentar distintas tipologias de inputs (estímulos ao sistema) advindos do visitante. Tais categorias são intituladas de estratégias conceituais, por se tratarem de aspectos projetuais mais subjetivos, ideias que, quando exploradas, podem estimular distintas formas de interação do usuário com os mediadores de conteúdo em museus.

Permeando as fundamentações teóricas das estratégias conceituais, são apresentados exemplos práticos de mediadores digitais de conteúdo em museus, a fim de ilustrar tais categorias. Tais casos foram escolhidos seguindo critérios de relevância para a fundamentação do recorte da pesquisa, partindo, principalmente, da utilização criativa da tecnologia como ferramenta para a transmissão de conteúdo nestes espaços culturais. Temse os próprios artefatos como fonte de dados, buscando apresentar suas respectivas ideias centrais e gerar reflexões - com base na teoria - a respeito das influências do uso destes para a experiência do visitante. Tal seleção de casos nacionais e internacionais se deu por meio de um estudo de reconhecimento baseado em uma coleta de ordem bibliográfica e iconográfica - a partir de catálogos, fotos, livros, artigos e demais publicações e empírica - por meio de visitas in loco em alguns museus selecionados - para uma análise observacional das estratégias utilizadas.

\section{ESTRATÉGIAS ESTRUTURAIS}

Conforme Mitchell (2009), identificar padrões não deixa de ser uma forma de simplificar um fenômeno real e complexo, cuja natureza precisa ser traduzida, de forma a mapear sua dinâmica, a fim de que possamos entendê-lo. Classificar um sistema ou um processo é, portanto, válido quando visto como modelos a serem, ou não, seguidos com o objetivo de entender melhor um fenômeno. É buscando uma maior clareza das questões centrais desta pesquisa que se apresenta a seguir uma sistematização de distintas análises teóricas, concentrando-se inicialmente por um estudo mais aprofundado da interação e de suas diferentes formas de outputs (respostas). Vale ressaltar que as categorias a seguir apresentadas dialogam entre si, e podem, por serem de distintas fontes, apresentar sobreposição de nomenclaturas e definições.

Os autores Dubberly, Pangaro e Haque (2009) em seu artigo What is interaction? are there different types? realizam, à luz da Cibernética de Gordon Pask (1976), uma sistematização da interação a partir do que eles chamam de sistemas dinâmicos. Para eles, ser interativo não é uma característica de um sistema em si, e sim da natureza da troca que é realizada entre distintos elementos de um sistema, os quais os autores classificam em três tipos essenciais: os 0 - lineares (linear systems), os 1 - auto-reguladores (self-regulating systems) e os 2 de aprendizado (learning systems).

Os sistemas lineares (de 0 ordem) reagem de forma padronizada aos estímulos a eles postos. Os autoreguladores (de $1^{\text {a }}$ ordem) se caracterizam por dar diferentes retornos a partir do tipo de input que lhes é dado, ajustando seu comportamento e variando suas respostas a partir do estímulo captado. Estas, contudo, são pré-definidas e encontram-se estabelecidas em seu objetivo (programação). Já os sistemas dinâmicos de aprendizado (de $2^{\mathrm{a}}$ ordem) caracterizam-se, não só por ajustar seu comportamento a partir dos inputs, como também por aprender com as mudanças nos estímulos recebidos. Com isto estes podem alterar, tanto os outputs, como também os próprios objetivos iniciais de sua programação. O sistema, assim, aprende com o usuário, e vice-versa, na forma de múltiplos ciclos, como uma espiral. Os autores afirmam que estas três características podem acontecer de forma independente ou podem se combinar, de forma a um sistema influenciar no comportamento do outro, havendo, assim, a interação a partir da mescla entre dois sistemas (Dubberly et al., 2009). Partindo destas combinações possíveis os autores elaboraram seis diferentes modelos, sendo por tal funcionamento conjunto que se ocorre a interação. É por meio de sua manipulação que se entende a lógica implementada em um artefato interativo, facilitando o processo de projeto, manipulação ou classificação de 
sistemas dinâmicos. A seguir apresentam-se, de forma resumida, as distintas combinações possíveis entre sistemas, a fim de exemplificar as categorizações futuramente apresentadas no presente trabalho.

Na classificação organizada por Dubberly, Pangaro e Haque (2009), as pessoas podem ser consideradas um sistema aprendiz, e sua interação com artefatos pode transitar em alguns desses padrões relatados. $\mathrm{Na}$ interação $0+0$, de reação, o input, é causado por meio de um estímulo em um dispositivo - cutucar, rodar, sinalizar, empurrar - a qual gera, segundo Pask (1976), uma reação pré-determinada, e muitas vezes limitada. Muitos dos artefatos mediadores de conteúdo em museus se caracterizam por serem apenas reativos, e esta escolha projetual, pode, muitas vezes, tornar a experiência rasa para o visitante, sem proporcionar estímulos mais enriquecedores nesta relação. $\mathrm{Na}$ interação $\mathbf{0 + 1}$, de regulação, um sistema linear gera uma perturbação em um sistema auto-regulador, o qual tem o objetivo de se manter equilibrado junto ao ambiente. Como, segundo exemplo dos autores, um motor a vapor ou um aquecedor (Dubberly et al., 2009).

A interação $\mathbf{0 + 2}$, de aprendizado, apresenta uma tipologia de interação que engloba muitas das interações humano-computador. Nelas, um sistema aprendiz (o humano) se combina com input linear. O sistema responde, e o humano se adapta aquele output. $\mathrm{O}$ ser humano pode aprender com o sistema, este, contudo, não aprende com o humano. Interações como estas não se caracterizam por permitir uma conversação propriamente dita, já que a máquina não aprende com os inputs trazidos pelo usuário. Vê-se, nesta classificação, que reagir a um input não é o mesmo que aprender, conversar, colaborar, ou até projetar. Saber desta diferença pode ser uma chave para novas formas de design. Substituir simples formas reativas por conversações apresenta-se como um possível, e desafiador, caminho para criar interações mais ricas e relevantes para o usuário. No $1+1$, de balanceamento, a interação é dada por dois sistemas auto-reguladores, e é dividida em dois tipos. Primeiro os que reforçam o mesmo objetivo, como dois ar-condicionados em uma mesma sala, ou os que competem entre si, como um arcondicionado e um aquecedor juntos em um mesmo espaço (Dubberly et al., 2009).

$\mathrm{Na}$ interação 1+2, de entretenimento, os autores destacam o exemplo de jogos eletrônicos, nos quais projeta-se um progressivo aumento da dificuldade de um jogo de acordo com o desenvolvimento do jogador. Tal estratégia projetual ocorre por meio da introdução de surpresas e desafios, o que renova e reforça a interação, contribuindo para o engajamento através do entretenimento. Desta forma os autores desta tipologia de interação encontram uma maneira de utilizar dos sistemas de regras e recompensas e desafios no sentido de um aumento da dificuldade de um sistema, com o qual o usuário realiza uma competição ou colaboração. Na interação 2+2, de conversação, há um processo cíclico de input e output, em que dois sistemas aprendizes conversam entre si (Dubberly et al., 2009). Permitir a conversação em uma interação entre conteúdo e visitante em museus não é uma tarefa fácil, pois exige que haja de fato uma troca entre sistemas.
Marcela Almeida (2014; 2016) - em sua tese e artigo a respeito da relação entre ambientes interativos e jogos inspira-se na classificação de Dubberly et al. (2009) e propõe três tipos de processos observados na relação humana com artefatos desta natureza. A interação classificada de reativa consiste em um sistema linear único de estímulo e resposta padronizado, ou seja, de causa (input) e efeito (output). Quando responsiva, a interação é caracterizada por dar diferentes respostas a partir de estímulos, sendo estes já predefinidos. Já quando dialógica, a interação consiste em um oferecer ao participante a possibilidade de atuar e modificar uma interface, estimulando uma maior colaboração entre pessoas e máquinas.

Dialogar é abrir possibilidade para a novidade dentro da interação. Conforme comenta Marques (2011, p.62) "a interação só é positiva se todos os envolvidos vislumbram a possibilidade da novidade - para usar o termo de Glanville (2001) - quer dizer, se caminham para o que Gordon Pask (1971) chama de "conversação" ou o que Flusser (2007) chama de "diálogo". Quando não há a novidade a "interação se transforma em algo fútil e não significativo, como o vazio de diversas obras de arte e jogos que se baseiam na ideia de interatividade por si, obstruindo a ideia fundadora de que há um outro ser desejante no outro lado do canal da interação" (Cabral Filho, 2005, on-line). Sugere-se, com isto, que há algo no elemento surpresa, e na imprevisibilidade de sistemas, que torna a interação mais efetiva para o usuário. A interação em si, lida com o indeterminado, é um produto de uma relação circular, não causal e sem controle (Glanville, 2001). Gordon Pask discute a importância da interação e a necessidade da novidade para que o homem se engaje em situações com o seu ambiente. "O homem está inclinado a procurar novidade em seu ambiente, e, tendo achado uma situação nova, a aprender a controlá-la" (Pask, 1971, p.76). Não é, portanto, uma simples ação e reação em sequência linear, e sim, um processo circular e imprevisível que ocorre entre a atividade do indivíduo e a ferramenta.

O artista Jim Campbell (2000) caracteriza as interfaces interativas de duas maneiras. A primeira como interface discreta, a qual ele cita o exemplo de um carpete no qual aciona-se uma imagem quando o visitante fecha o circuito ao pisar em um botão. A pessoa ali não interage com o programa ou com a imagem, apenas com o botão, não havendo diálogo, apenas os estados de ligado e desligado. A segunda forma de classificação de Campbell caracteriza-se por interface contínua, a qual ocorre, por exemplo, quando em um carpete se dispõem de 100 botões, e ao se pisar individualmente em cada um deles, uma de 100 distintas respostas são geradas e refletidas em um monitor, o qual é estimulado a partir do mapeamento da posição do ser humano. A interface ali não deixa de ser digital, e, portanto, discreta, entretanto o autor destaca que o importante é a forma como a mensagem chega na percepção do visitante, e como os efeitos de resposta mostram-se a ele de forma contínua, sendo percebida de maneira categoricamente diferente quando comparado ao primeiro exemplo relatado (Campbell, 2000).

Ruairi Glynn - arquiteto, artista e mídia designer - para melhor entender e desenvolver a prática de projetos interativos, classifica-os em três tipos, a partir de suas

3 
reações a estímulos (Glynn, 2008). O primeiro tipo parte de uma reação automática, possuindo apenas dois estados, ligado e desligado. Esta tipologia de reação caracteriza-se por ser independente de inputs externos. A segunda forma classifica-se como reativa, e age de acordo com critérios anteriormente definidos. Segundo Glynn (2008), em muitos casos, esta natureza de output é erroneamente caracterizada como interativa. A reação interativa para ele, portanto, só pode ser considerada assim quando há uma autonomia do próprio sistema, com a possibilidade deste de, por diferentes meios, atingir os objetivos estabelecidos inicialmente na programação. Os caminhos são, portanto, definidos de maneira variável. De forma cíclica, input e output se retroalimentam, possibilitando que a própria estrutura do algoritmo sofra alterações a partir dos estímulos recebidos. Tal forma ampla de possibilidades, permite que o próprio sistema faça uso de improviso, aprendizado e negociação para alcançar os objetivos programados (Carneiro, 2014).

Ao tratar de mídias interativas, Jensen (2008, p.129) define interação como "uma medida da habilidade potencial de uma mídia de permitir que o usuário exerça uma influência no conteúdo e/ou a forma da comunicação mediada". Partindo desta definição ela descreve quatro sub-conceitos de interação: Interação de transmissão, a qual consiste em uma mídia de "mão única", como uma TV que não permite aos usuários fazer solicitações outras além de trocar o canal; interação de conversa, na qual há um compartilhamento de "mão dupla", como uma troca de e-mail; interação de consulta, na qual há uma possibilidade de permitir que o usuário escolha uma informação pré-produzida, como um web site na internet; interação de registro, na qual há uma automatização das respostas dadas aos dos usuários, por meio de suas necessidades e ações, ela dá como exemplo métodos de sistemas que sentem automaticamente estímulos do ambiente e se adaptam, como sistemas de segurança, home-shopping, luz automática da interface do smarphone, etc. Preece, Sharp and Rogers (2015) trazem o conceito de interação a partir de classes, considerando também a forma de interação, as quais são divididas em quatro principais: instrutiva, quando são transmitidas instruções a um sistema; conversativa, quando o usuário dialoga com o sistema; manipulativa quando os usuários interagem com objetos em ambientes virtuais ou físicos pela manipulação destes; e explorativa quando os usuários se movem por um ambiente virtual ou físico.

Nota-se, tendo em vista as classificações apresentadas, que há um padrão de categorização de outputs na interação humano-computador. Em suma, os autores buscam sistematizá-las, em geral, com base em: 1) um output automatizado, com retorno padronizado, no qual o participante tem poucas, ou apenas uma, possibilidade de estímulo; 2) em um output também padronizado, entretanto, com variáveis possíveis a depender do estimulo provocado, o que possibilita uma multiplicidade de inputs por parte do usuário, permitindo maior desenvoltura nos estímulos e respostas de um sistema; ou 3) interações que permitem uma retroalimentação entre inputs e outputs, como uma conversa, um diálogo entre humano e sistema, sendo este não padronizado, cíclico e cambiante. Compreender a interação dentro destas tipologias de outputs abrem possibilidades para formas de mapeamento e classificação de formas diversas de transmissão de conteúdo em museus, bem como também levam a um exame de estratégias projetuais que fomentem novos inputs por parte dos usuários. Entender como fomentar as ações humanas é, para este artigo, uma maneira de entender como tornar as mediações de conteúdo mais engajadoras. Por este motivo o item a seguir aponta, com base nos referenciais teóricos supracitados, as contribuições dos autores deste artigo para um melhor entendimento de aspectos conceituais propostos, classificados em categorias, acompanhadas de exemplos, a fim de auxiliar no projeto de futuras mediações desta natureza.

\section{ESTRATÉGIAS CONCEITUAIS}

A seguir são apresentadas as classificações das estratégias no sentido conceitual. O conceito aplicado ao ato projetual, segundo Leupen (1999), se baseia em aspectos abstratos que tem a função de dar coerência, expressando sua ideia base, subjacente ao desenho, que guia as decisões do projetista em determinada direção, excluindo e acrescentando pontos necessários na busca de uma excelência conceitual. Quando utilizados como decisões e ferramentas subjetivas ao projeto, são aspectos que podem ter o potencial de fomentar e enriquecer os estímulos e a experiência humana em interação. Ainda que não seja possível projetar-se experiências propriamente ditas, o design dispõe de meios para gerar produtos, sistemas e situações que permitam que os usuários possam ter suas experiências a nível individual ou coletivo (Sakurai, 2012). Desta forma apresentam-se a seguir padrões pontuais, tomando como base aspectos teóricos vistos como pertinentes para cada elemento desta classificação, seguidos por exemplos práticos escolhidos.

\subsection{MANIPULAÇÃO DE OBJETOS FíSICOS}

Conforme apontado no item de estratégias estruturais, Preece, Sharp e Rogers (2015) trazem o conceito de interação manipulativa, sendo esta quando os usuários interagem com objetos analógicos como meio de interação com a interface digital. Desta forma o visitante utiliza de algo manipulável fisicamente para assim realizar os inputs necessários no sistema. De forma análoga, Gibson (1979), em seu livro The Ecological Approach to Visual Perception - publicado em 1979 - elabora originalmente um conceito que possibilita melhor entender a interface e a relação humana com objetos, ao estudar a percepção visual dos seres humanos. Para ele, o ambiente fornece elementos para que os animais interajam com ele, e estes elementos são chamados de affordances. Tal conceito é trazido para a Interação Humano-Computador (IHC) por Donald Norman, e foi amplamente discutido ao longo dos anos. Para Norman (1988), affordances são as possibilidades de ação fornecidas pelo ambiente, servindo como uma ferramenta que proporciona fortes pistas visuais para a operação das coisas. Objetos possuem, portanto, propriedades de como estes podem ser utilizados, as quais podem ser percebidas. "Os botões são para apertar. As maçanetas são para girar. Os entalhes são para introduzir coisas dentro. Bolas são para jogar ou saltar." (1988, p.9). Desta forma, conhecer estas possibilidades é dar aos seres humanos, por meio do projeto, a capacidade de melhor interagir com o ambiente e com os artefatos ao seu redor.

Dentro destas possibilidades de ação para a operação das coisas, utilizar de artefatos físicos para mediar a 
relação com o conteúdo virtual pode ser uma estratégia efetiva no sentido de provocar novas possibilidades de interação e engajamento. Um escritório que faz algumas experimentações neste sentido é o Ideum Design, desenvolvendo uma tecnologia de mesa tátil (Tangible Engine Media Creator), na qual o visitante pode colocar objetos reais e obter informações sobre os mesmos. Um exemplo de projeto elaborado por eles é o Planes of Fame Air Museum, na Califórnia (fig. 1), esta tecnologia é utilizada para obter informações a respeito de estratégias de bombardeio dos EUA na $2^{\mathrm{a}}$ guerra através das histórias dos próprios aviões que lá lutaram. Ao colocar um modelo específico sobre a mesa digital, informações a respeito de suas campanhas, design, armamentos e dos pilotos que os utilizaram são graficamente demonstradas em animações interativas.

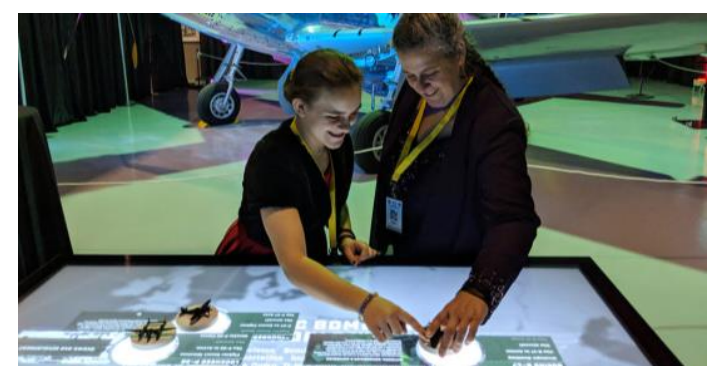

Figura 1: Exposição Planes of Fame Air Museum. Fonte: <https://ideum.com/portfolio/planes-of-fame>

Outro exemplo de museu que optou por utilizar da materialidade de um instrumento físico para auxiliar na comunicação com o meio digital é o Cooper Hewitt, Smithsonian Design Museum, em Nova York. Com o auxilio do escritório Local Projects eles desenvolveram uma série de projetos interfaces digitais nas quais é possível interagir de distintas formas, sendo a principal forma por um instrumento físico, a "the Pen" (figuras 2 e 3), uma caneta que é emprestada ao visitante para que este registre as obras e informações que lhe foram interessantes da visita. Esta não só serve como um banco de armazenamento para futuro acesso a informações dos objetos que mais o interessaram, como também permite que este desenhe formas e composições gráficas através de dispositivos espalhados pelo espaço do museu. Com isso, o visitante também se torna criador, e entende melhor o processo de design - tema para qual o museu se volta. (Chan e Cope, 2015).
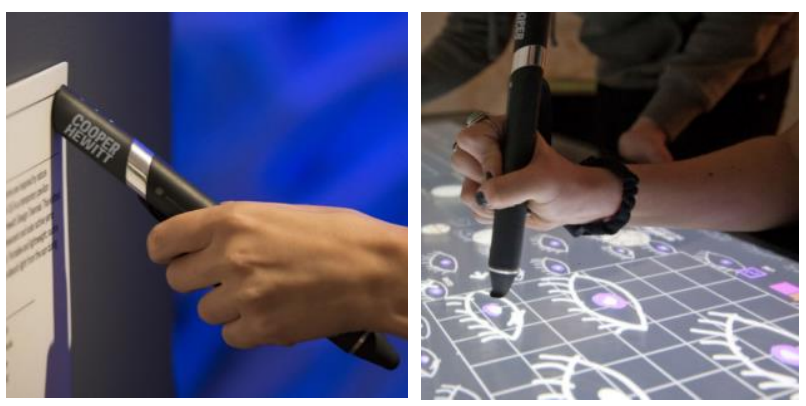

Figura 2 e 3 : Imagens da utilização da "the Pen". Fonte: (Chan e Cope, 2015).

\subsection{CORPO COMO CONTROLE}

Novas tecnologias têm permitido que o corpo como um todo, e não apenas os dedos e as mãos, se tornem as ferramentas para a interação com meios digitais. Paul Dourish (2004) aprofunda o conceito de embodiment na interação ao abordar as novas possibilidades da tecnologia em se adaptar às características físicas humanas, tornando-as mais próximas das necessidades dos usuários. Possibilitar o uso do corpo como ferramenta de interação pode ser uma importante forma de fomentar interações mais engajadoras e conectadas com o ambiente nos espaços museológicos.

A experiência Gallery One (Figuras 4 e 5), proposta pelo escritório Local Projects, no Museu de Arte de Cleveland, em Ohio, o qual, além de ser um exemplo notório de uma aplicação de interface dialógica entre conteúdo museológico e visitantes, faz uso do corpo do usuário como mecanismo de controle da interface. Nela o visitante pode interagir de variadas formas com o amplo conteúdo disponível no acervo do museu. Uma das interfaces propostas na experiência se dá por uma câmera conectada a um monitor, a qual coleta a posição corporal ou a expressão facial do visitante, com esse dado - a partir de um mapeamento de pontos por meio de algoritmos de detecção de corpo e face - o sistema apresenta uma imagem de alguma obra do museu, pintura ou escultura, a qual se assemelhe ao gesto realizado pelo visitante. Com isso, cria-se uma identificação deste para com a obra, sobre a qual ainda é disponibilizado informações relevantes, incentivando o usuário a vê-la ao vivo e conhecer mais a seu respeito, criando assim uma relação lúdica e social entre os outros visitantes da galeria.
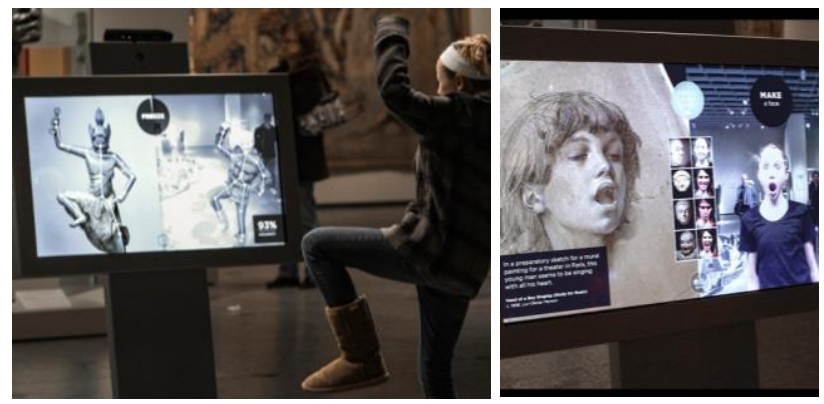

Figura 4 e 5 : Imagens da interação corporal dos visitantes com a interface Gallery One. Fonte: <https://segd.org/content/galleryone-cleveland-museum-art>

Outro exemplo que utiliza o corpo do visitante de forma notória é o Museu Micropia, em Amsterdam. Este espaço recebeu o prêmio de museu mais inovador da Europa no ano de 2016 (EMYA Awards). Tal reconhecimento se dá muito pela originalidade do tema e de sua expografia, a qual utiliza de diversas mídias para apresentar aos visitantes a vida dos micróbios. Além disso, o espaço também serve de ponte entre a comunidade científica e o público, o qual pode participar de apresentações participativas e acompanhar verdadeiros cientistas realizando experimentos. Uma das interfaces digitais de transmissão de conteúdo mais populares é o body scan (figuras 6 e 7), projetada pelo escritório alemão $A R T+C O M$. Esta instalação consiste em um sensor que detecta os movimentos humanos e transmite informações a respeito dos micróbios importantes para o funcionamento de diversas partes do corpo humano, como os olhos, boca e estômago, por exemplo. Em visita o pesquisador notou que esta possibilidade de interação não só se concentra nos dados transmitidos, como também gera diversas outras tipologias de comunicação 
entre os visitantes, havendo muitas criações de jogos, de danças e outras relações sociais frente ao sensor.
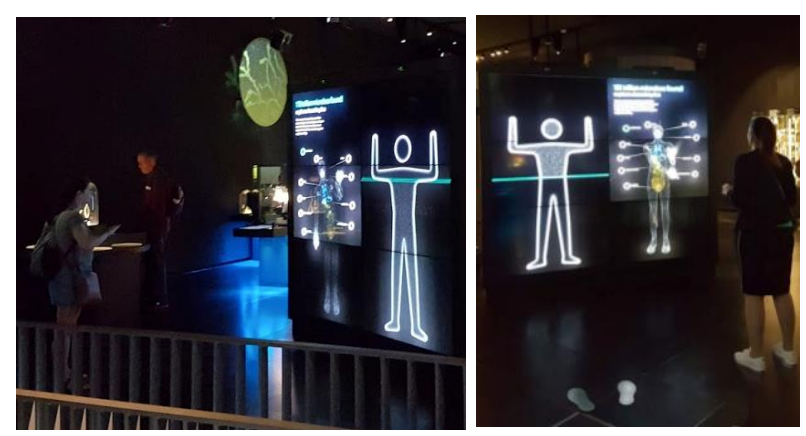

Figura 6 e 7 : Imagens da interação corporal dos visitantes com o body scan do museu Micropia. Fonte: Acervo dos autores.

\subsection{MATERIALIZAÇÃO DA INTERAÇÃO}

Notou-se que algumas técnicas conceituais utilizam de abertura das possibilidades de interação com um sistema para fazer com que o visitante seja efetivamente partícipe no processo de interação. Com isso o usuário não só pode alterar o sistema com inputs próprios, como também gera um objeto virtual, ou imagem, que serve como um símbolo desta participação, o qual ele pode guardar ou compartilhar em redes sociais, gerando maior interesse e divulgação da exposição para o grande público. Um exemplo de uso desta estratégia apresenta-se no Museum of Contemporary Native Arts (IAIA), em Santa Fé, Novo México. Neste museu há uma interface (figura 8), projetada pelo escritório Ideum Design, na qual o visitante é convidado a experimentar com elementos estruturais das malhas indígenas de forma a criar sua própria a partir destes conceitos de linguagem visual básicos presentes na cultura tradicional das tribos ali representadas.

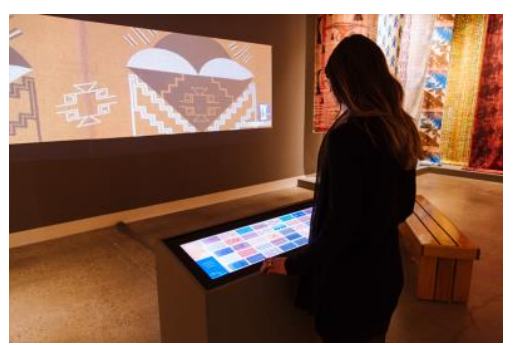

Figura 8: Interface para criação de malhas indígenas.

Fonte: <http://ideum.com/portfolio/textile-viewer-creator>

O Museu Cooper Hewitt, conforme apresentado ao mostrar o exemplo da "the Pen", traz um bom exemplo de como gerar mais engajamento por meio da participação dos visitantes ao torná-los também agentes da transformação do espaço do museu. Esta instituição possui o maior acervo de papéis de parede do mundo, entretanto, não há espaço suficiente para deixa-los em exposição. A solução encontrada para apresenta-los e também para ensinar ao visitante do processo de criação e desenvolvimento desta natureza de design, foi criar uma interface em que é possível utilizar a caneta para desenhar padrões gráficos. Assim é gerada uma composição por repetição de padrões, a qual é projetada em uma parede real do museu (figuras 9 e 10). A criação pode ser salva na própria caneta e enviada para o e-mail do usuário, para que este possa imprimi-la em alta resolução, gerando o seu próprio papel de parede. O fato de haver uma abertura para que o visitante possa alterar a exposição, é um meio para torná-lo cada vez mais parte integrante, criadores e partícipes da modificação do espaço museológico.
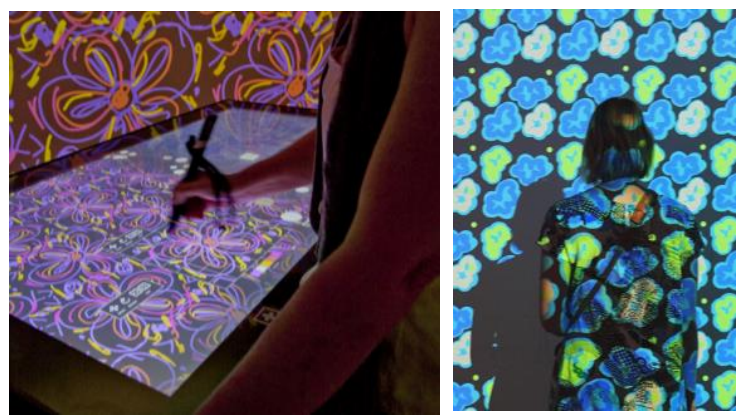

Figura 9 e 10 : Imagens do Wallpaper Room.

Fonte: <http://localprojects.com/work/cooper-hewitt-smithsoniandesign-museum>

\subsection{REGRAS}

Regras também se apresentam como estratégias de projeto de mediadores tecnológicos que podem enriquecer a experiência de visitação em um museu. Desta maneira, segundo Carneiro (2014), as regras podem dividir-se entre implícitas ou explícitas. Quando explícitas, estas mostram-se efetivas quando a intenção é estimular uma interação mais direcionada, possibilitando um engajamento em tempo mais curto, que, no entanto, pode ser bem efetivo na transmissão de conteúdo, pois não deixa ambiguidades, ou dúvidas de como proceder. Não saber o que fazer ao estar de frente a um artefato mediador pode, em muitos casos, ser o motivo de um eventual desinteresse, ou frustração, por parte do público. No caso de regras implícitas, o engajamento pode vir exatamente da tentativa de entender como o sistema funciona, de como os inputs gerados pelo usuário alteram o sistema, bem como de que maneiras distintas estes estímulos podem ser identificados experimentados de outras formas.

Um exemplo de regras implícitas ocorre na experiência River of Grass, realizada pelo escritório Formula $D$ no Frost Science Museum, em Miami, Flórida. Esta experiência imersiva se dá por meio de um misto entre projeção e artefatos físicos com os quais as crianças podem manipular as imagens e animações presentes. Tem-se o objetivo de ensinar as crianças a respeito do ecossistema único presente na região de Everglades, na Flórida. Neste espaço as crianças são convidadas a se engajarem em uma variedade de brincadeiras que vão desde correr atrás de animais, espantar mosquitos, e interagir com peixes. Como exemplo de uma das regras implícitas, os usuários são recompensados com animações variadas quando repetem as poses e movimentos dos animais. Como pode ser visto na figura 11 , troncos artificiais também podem ser movimentados para gerar experimentações com o fluxo das águas dos rios e também no movimento dos peixes ali projetados. No período da noite, na animação, se apresentam novas possibilidades ao se utilizar de lanternas com o objetivo de caçar animais noturnos escondidos na paisagem. Nota-se que a presença de regras subliminares só trouxe para os usuários mais possibilidades de engajamento e interações sociais. Quando se descobre que um input específico causa determinada resposta, isto torna-se um incentivo para uma maior vontade da criança de participar e desbravar novas possibilidades. 


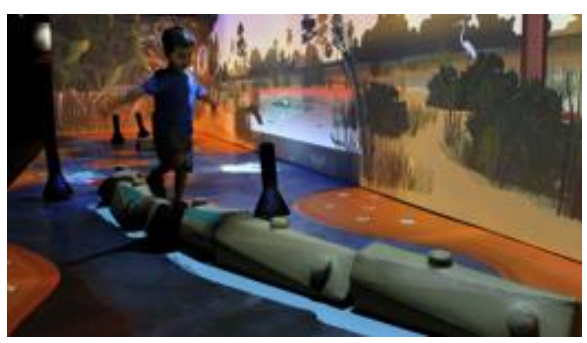

Figura 11: Exposição River of Grass

Fonte: < https://formula-d.com/projects/virtual-everglades-tunnel/>

Outro exemplo que se aplica no quesito de regras implícitas é a caixa de areia do Museu Catavento Cultural, em São Paulo (figuras 12 e 13). Chamada de Relevos da terra $3 D$ essa interface foi projetada pelo pesquisador Oliver Kreylos, da Universidade da Califórnia, e disponibilizada para gratuito uso ao redor do mundo. Esta interação consiste em uma caixa de areia na qual é projetada - por realidade aumentada - uma imagem de relevos e curvas de nível a partir da altura que se encontram os montes e declives criados pelo próprio visitante a partir da manipulação da areia. O projetor é conectado a um computador integrado à um Kinect, o qual percebe as distancias e modifica em tempo real a imagem projetada. Com este mediador, o museu consegue passar ao visitante conteúdos gerais relativos a topografia, bem como a criação de rios e lagos. A regras para uso não estão totalmente explícitas na expografia, o que permite que o visitante busque formas de entender e interagir com o dispositivo. Isso se mostra ainda mais claro quando o visitante coloca a mão sobre a areia - em uma altura onde proporcionalmente estariam as nuvens podendo observar a geração de uma chuva projetada sobre a superfície, com a qual formam-se rios e lagos a partir da topografia proposta pelo usuário. Este é um exemplo prático que mostra o sistema cíclico de retroalimentação de input e output pré-programado efetivamente aplicado a um mediador de conteúdo em museus. Desta forma o sistema permite que o usuário não só gere estímulo, como também modifique o sistema por meio de uma alteração em sua forma física.
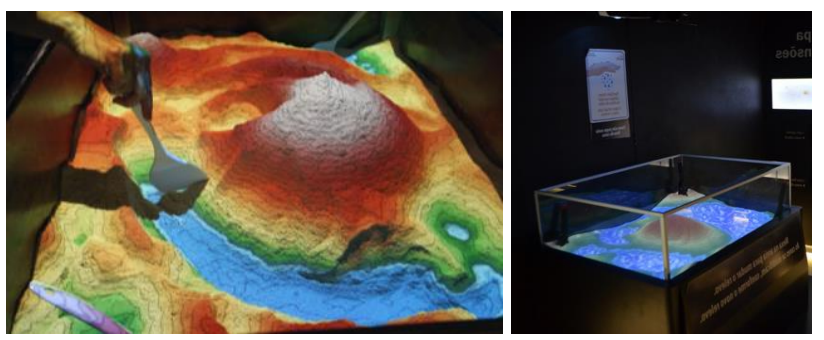

Figura 12 e 13: Figuras da Exposição Relevos da Terra 3D. Fonte:

Fonte: < http://www.cataventocultural.org.br/four_sections >

\subsection{RELAÇÕES SOCIAIS}

O incentivo da interação por meio de regras é também um elemento estruturante dos jogos, sejam eles analógicos ou digitais. Dentro disso, como visto no item de estratégias estruturais, Dubberly et al (2009) apresentam a classificação de entretenimento $(1+2)$ a qual se caracteriza pelo uso de regras, surpresas e desafios para reforço da interação. Tais características estimulam as relações sociais, sejam elas de natureza colaborativa ou competitiva, levando a um exame da importância destas para fomento do engajamento de visitantes. Segundo o pesquisador Dirk Vom Leh, ao realizar extensa pesquisa por vídeo de interações de visitantes em museus, a maneira como o visitante vê e sente o espaço expositivo é diretamente influenciada pela sua interação social. As pessoas compartilham suas experiências com os outros seja com conhecidos ou não - através de ações verbais ou corporais (Vom Lehn, 2006). Almeida (2016), em seu artigo relacionando jogos e ambientes interativos, traz que 0 aspecto social pode ser o elemento-chave para tornar a experiência verdadeiramente dialógica. Glanville (2001), por exemplo, traz o conceito de interação relacionado a um processo que ocorre entre participantes. Quando se coloca o humano, a interação torna-se indeterminada, tornando-a, de fato, uma conversação.

O fomento aos inputs pelas relações sociais foi observado em alguns exemplos de artefatos mediadores de conteúdo. Um destes que se destaca está no Museu Cais do Sertão em Recife, o qual tem projeto expositivo de Isa Grinspum Ferraz e projeto arquitetônico do escritório Brasil Arquitetura. Neste museu há o Jogo da Seca (figuras 14 e 15), no qual o cantor Tom Zé narra um jogo interativo de desafios estratégicos para acabar com o problema da seca no sertão nordestino. O sistema do jogo se baseia na competição entre participantes. 0 ganhador é aquele que efetuar mais soluções que não apenas resolvam o problema das secas momentaneamente, mas a longo prazo. Desta forma este mediador consegue criar engajamento e gerar uma interação educativa entre visitantes.
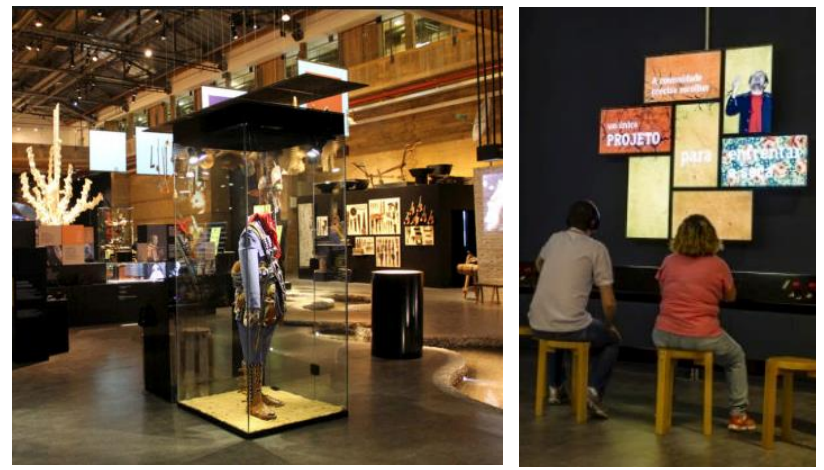

Figuras 14 e 15: Imagens relativas ao Jogo da Seca. Fonte: < https://janelasabertas.com/2014/07/18/museu-cais-sertao/>

Outro exemplo também visitado pelo pesquisador se encontra no museu ARos, na cidade de Arhus, na Dinamarca. Esta instituição, buscando ter uma relação mais próxima com a comunidade, criou o ARoS Public, sendo este um espaço também projetado pelo escritório Local Projects, e voltado a diversas atividades com os visitantes. Durante entrevista presencial realizada para esta pesquisa, Marianne Grymer - diretora do setor de aprendizado e interpretação do museu e peça chave do projeto - informou que, dentre as ações propostas no projeto do ARoS Public, estão os ateliês, os estúdios e as três estações digitais interativas, as quais foram pensadas primeiramente em sua ideia e objetivos principais, para depois chegar-se na tecnologia adotada para cumprir tais quesitos. Dentre as três estações interativas estão duas que fomentam as interações sociais, sendo estas: 1) uma cabine de poses (figura 16) a qual joga com o movimento corporal, ao lançar posições que quando reproduzidas pelo usuário, geram imagem randomicamente elaboradas utilizando de partes das obras do acervo; 2) uma cabine de gravação (figura 17), na qual dois ou mais participantes são convidados a responder perguntas sobre as obras. Parte notória desse 
sistema é que ele não lança perguntas voltadas a testar conhecimento, e sim questionamentos estimulantes que fomentam diálogos e interações sociais entre os visitantes. O material gravado transforma-se em um GIF e pode ser enviado por e-mail para livre uso do visitante.
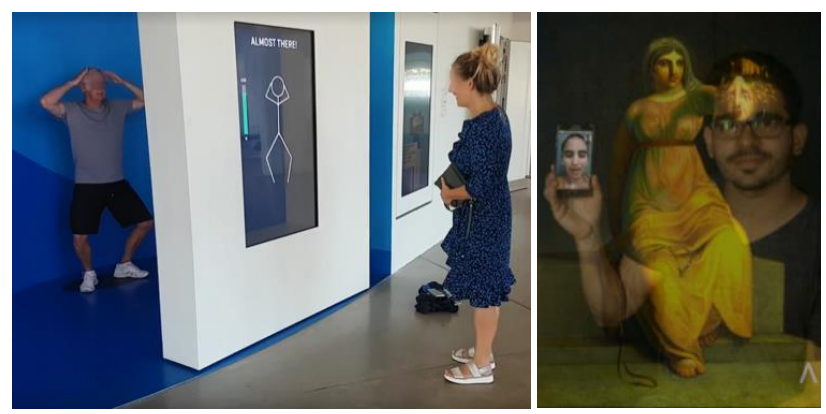

Figura 16 e 17: Duas das três estações digitais interativas do ARoS Museum. Fonte: Acervo do autor.

\subsection{NARRATIVA}

Percebe-se explorar a narrativa (storytelling) pode ser uma técnica relevante para tornar a experiência do visitante memorável, sendo também um artifício importante para a existência de uma lógica interna, a fim de que o projeto do artefato possua um conceito coerente quanto a emissão da mensagem que se deseja transmitir. O uso bem explorado desta ferramenta permite que aspectos subjetivos do usuário sejam estimulados - como memórias, fatos, analogias e metáforas - no sentido de fomentar o engajamento do visitante em uma experiência.

A narrativa pode ser caracterizada como uma ferramenta destinada a fazer com que os usuários dediquem tempo suficiente a uma ação de forma a criar camadas de conexão emocional com uma atividade. Destaca-se, contudo, que se deve garantir que tal experiência não ultrapasse longos período de tempo de forma a induzir um estranhamento por parte do usuário (Chapman, 2015). Por ser uma técnica por vezes poderosa no sentido de transmitir ideias, é também uma ferramenta de apelo didático, tornando conceitos complexos mais facilmente transmitidos. Por estas qualidades, é também uma sedutora alternativa que em muitos casos serve como meio de manipulação e convencimento ilusório, devendo ser usada com cautela para que o projetista não acabe entrando por vias excessivamente mercadológicas e rasas de conteúdo (Sakurai, 2012).

Um exemplo de aplicação desta ferramenta foi realizado no Memorial 11/09 (figuras 18 e 19), projetado pelo escritório Local Projects, em nova York, o qual faz uso da capacidade do usuário de modificar a exposição por meio da narrativa. Baseia-se em uma interação que ocorre de forma direta, e sim, por meio do próprio depoimento do visitante, o qual é convidado a ser parte integrante da exposição. Isto é feito ao ser coletado a história oral de distintas experiências com o atentado do 11 de setembro, criando diversas formas de apresentação de trechos destas falas. Esses depoimentos são mesclados com acontecimentos da vida dos que se foram. Tudo isso é transmitido através de áudio, projeções e outras mídias diversas ao longo do espaço expositivo, as quais são apresentadas por meio de algoritmos que organizam constantemente a forma que estes dados são transmitidos. Desta maneira o conteúdo nunca é o mesmo, de forma a ressaltar as pessoas, suas memórias e a história dos que tiveram suas vidas impactadas pela tragédia. O memorial valoriza, portanto, a experiência por meio de um museu de memórias coletivas, criando conexões entre pessoas, bom como uma relação mais profunda e simbólica com o que se quer transmitir.
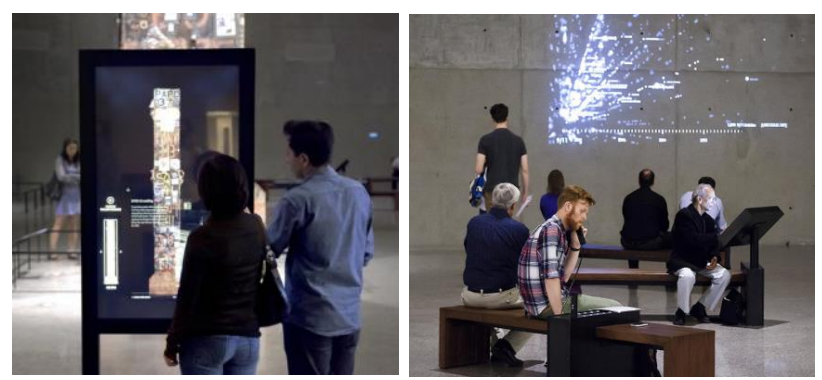

Figura 18 e 19: Figuras da Exposição do Memorial 9/11 Fonte: $<$ https://localprojects.net/work/911-memorial-museum-groundzero>

\section{CONCLUSÃO}

Nesta pesquisa foram apresentadas algumas possibilidades de estratégias projetuais, pela qual foi realizada uma reflexão das técnicas utilizadas e as possíveis consequências do uso destas para tornar o museu mais atrativo para novos públicos. Teve-se o intuito, com esta estratégia metodológica, de apresentar análises a cerca de tais estratégias, bem como, as possíveis consequências destas para a experiência dos visitantes. A forma de classificação realizada se voltou a citação de exemplos práticos, a fim de refletir as distintas possibilidades de uso de tecnologia digital em mediadores de conteúdo em museus. Com os casos elencados e as análises propostas foi possível inferir que diferentes estratégias projetuais podem relacionar-se diretamente com aspectos subjetivos dos visitantes, permitindo que novos usuários se sintam incentivados a engajar-se nestas experiências, ampliando as camadas sociais de atuação das instituições museológicas, bem como, as possibilidades inovadoras de transmissão de conteúdo.

Quando tratando das estratégias estruturais foi citado que os autores e especialistas citados tratam de maneira semelhante a respeito de interação. Ao utilizarem nomenclaturas distintas, muitos buscam definir uma mesma essência estrutural presente nos ambientes de fato interativos. Em suma, o que estes autores trazem, é uma divisão a partir da maneira como o tipo de rotina lógica de estímulo (input) e resposta (output) é implementado. Para trabalhos futuros interessa notar como esta busca por uma relação mais significativa com a máquina se repete em diversos autores, aprofundando nos pontos em que estas se distinguem.

Ao refletir a respeito das estratégias conceituais aplicadas nos casos elencados, colocou-se questões relativas a própria noção do uso de instrumentos para estimular a relação dos seres humanos com o mundo. Ao analisar, entretanto, técnicas de transmissão de conteúdo em museus, nota-se, muitas vezes, uma dificuldade nesta mediação. Motivo pelo qual estas formas de transmissão devem ser pensadas com cautela, para não se tornar algo preso na utilização da tecnologia por si só. Como avalia o físico espanhol Jorge Wagensberg, conhecido 
por transformar a abordagem museológica em ciência, e tido como um dos grandes pensadores de museus na atualidade:

a. "A tecnologia caduca sempre muito rapidamente. As boas ideias, por outro lado, não caducam jamais. É nisso que os museólogos nunca devem economizar: as boas ideias para explicar boas histórias com inteligência e beleza! (...) (Furlaneto, 2013)

Percebe-se que a interatividade no nível dialógico é um desafio a ser alcançado, e que poucos casos - como o Aros Museum, o Cooper Hewitt, Smithsonian Design Museum e a Gallery One no Cleveland Museum of Art se apresentam como bem-sucedidos neste sentido. Com os casos analisados pode se supor que, para a instituição museológica, optar por permitir a interação, é dar ao visitante a possibilidade de alterar os estímulos e as respostas do sistema, de forma que o projetista não deve limitar as possibilidades, e sim ampliá-las, explorando positivamente a existência de regras e limitações. Conforme afirma Almeida (2014), quando se busca tal nível de diálogo sem um critério "corre-se o risco de a interface ser tão aberta que favoreça pouco a interação, por não estimular a ação" (De Almeida, 2014, p.181).

\section{AGRADECIMENTOS}

Esta pesquisa é parte da dissertação de mestrado em Design da Faculdade de Arquitetura e Urbanismo da USP do primeiro autor do artigo. Foi financiada pela Coordenação de Aperfeiçoamento de Pessoal de Nível Superior (CAPES). O material teve também parte dos dados coletados realizados graças a uma bolsa fornecida pelo banco Santander e organizada pela Unión Iberoamericana de Universidades (UIU), com a qual foi possível visitar alguns dos casos apontados no presente artigo. Agradecemos pelo apoio concedido.

\section{REFERÊNCIAS}

BOELTER, V. Design de Exposição na Arte e Tecnologia Digital: uma prática em construção. Estudos em Design, v. 24, n. 3, 2016. ISSN 1983-196X.

CABRAL FILHO, J. D. S. Um futuro além da transgressão: interação e automação: ataques à solidão. In: (Ed.). Corpo e Arte: estudos contemporâneos. São Paulo: Nojosa Edições, 2005. p.31-42.

CAMPBELL, J. Delusions of dialogue: control and choice in interactive art. Leonardo, v. 33, n. 2, p. 133-136, 2000. ISSN 0024-094X.

CARNEIRO, G. P. Arquitetura interativa: contextos, fundamentos e design. 2014. (Tese de doutorado). Faculdade de Arquitetura e Urbanismo, Universidade de São Paulo.

CHAN, S.; COPE, A. Strategies against Architecture: Interactive Media and Transformative Technology at the Cooper Hewitt, Smithsonian Design Museum. Curator: The Museum Journal, v. 58, n. 3, p. 352-368, 2015. ISSN 2151-6952.

CHAPMAN, J. Emotionally durable design: objects, experiences and empathy. Routledge, 2015. ISBN 1317574826 .

DE ALMEIDA, M. A. Ambientes interativos: a relação entre jogos e design para a interação. 2014.

A teoria da ludificação e os ambientes responsivos. Blucher Design Proceedings, XX SIGraDi. v. 3, n. 1, p. 838-843, 2016. ISSN 2318-6968.

DOURISH, P. Where the action is: the foundations of embodied interaction. MIT press, 2004. ISBN 0262541785.
DUBBERLY, H.; PANGARO, P.; HAQUE, U. What is interaction?: are there different types? interactions, v. 16, n. 1, p. 69-75, 2009. ISSN 1072-5520.

FLUSSER, V. O mundo codificado: por uma filosofia do design e da comunicação. São Paulo: Cosac Naify, 2007.

FURLANETO, A. Futuro dos museus está na criatividade e não na tecnologia, dizem especialistas reunidos no Rio. $2013 . \quad$ Disponível em: < https://oglobo.globo.com/cultura/futuro-dos-museus-esta-nacriatividade-nao-na-tecnologia-dizem-especialistas-reunidosno-rio-9455603>. Acesso em: 25/06/2017.

GASPARETTO, D. A. Arte-ciência-tecnologia:: o sistema da arte em perspectiva. Débora Aita Gasparetto (Org.), 2014. ISBN 8568185002.

GIBSON, J. J. The theory of affordances The Ecological Approach to Visual Perception (pp. 127-143): Boston: Houghton Miffin 1979.

GLANVILLE, R. And he was magic. Kybernetes, v. 30, n. 5/6, p. 652-673, 2001. ISSN 0368-492X.

GLYNN, R. Conversational environments revisited. na, 2008.

JENSEN, J. F. The concept of interactivity--revisited: four new typologies for a new media landscape. 2008, ACM, 2008. p.129-132.

LEUPEN, B. Proyecto y análisis: evolución de los principios en arquitectura. 1999.

MARQUES, L. M. S. O museu Beta: estratégias para um museu sempre contemporâneo. 2011. (Dissertação de mestrado). UFMG

MARX, K. O Capital, vol. 1, livro 1. Rio de Janeiro: Brasileira, v. 2, 1985.

MENESES, U. T. B. Os Museus na era virtual. XVI Seminário Internacional "Museus, Ciência e Tecnologia"/MHN-Rio, 2006.

MENESES, U. T. B. D. Museu virtual é o museu do futuro. Musas, ano, v. 2, 2009.

MITCHELL, M. Complexity: A guided tour. Oxford University Press, 2009. ISBN 0199724571.

NORMAN, D. The design of everyday things (originally published: The psychology of everyday things). The Design of Everyday Things (Originally published: The psychology of everyday things), v. 20, 1988.

OGILVY; IBM; PINACOTECA. A Voz da Arte - IBM Watson. Youtube: 3:31 p. 2017.

PASK, G. A comment, a case history and a plan. Cybernetics, Art and Ideas, p. 76-99, 1971.

Conversation theory: Applications in education and epistemology. Elsevier Publishing Company, 1976. ISBN 044441424X.

PREECE, J.; ROGERS, Y.; SHARP, H. Interaction design: beyond human-computer interaction. John Wiley \& Sons, 2015. ISBN 1119020751.

SAKURAI, T. Memorabilia: critérios para o design de mobiliário doméstico para a experiencia. 2012. (Tese de doutorado) Faculdade de Arquitetura e Urbanismo, Universidade de São Paulo

VOM LEHN, D. Embodying experience: A video-based examination of visitors' conduct and interaction in museums. European Journal of Marketing, v. 40, n. 11/12, p. 1340$\begin{array}{lll}\text { 1359, } 2006 . & \text { ISSN } & 0309-0566 .\end{array}$ 